\title{
Gaviscon and Carobel compared with cisapride in gastro-oesophageal reflux
}

\author{
P Greally, F J Hampton, U M MacFadyen, H Simpson
}

\begin{abstract}
We compared the efficacy of the prokinetic agent cisapride with that of Gaviscon (an alginate/alkaline compound) plus Carobel (carob seed flour) in the treatment of gastrooesophageal reflux (GOR). Fifty infants with confirmed GOR received either oral cisapride $(0.8 \mathrm{mg} / \mathrm{kg} / \mathrm{day})$ or Gaviscon plus Carobel for one month in a randomised, parallel group study. Parental evaluations, diary scores, and 24 hour lower oesophageal $\mathrm{pH}$ recordings before and at the end of each treatment were compared.

In the cisapride group 14/26 (53\%) were considered better by their parents compared with 19/24 (79\%) of those who received Gaviscon plus Carobel. Diary scores, range (0.00-1.00), improved in both groups with the median change being greater in the Gaviscon plus Carobel group $(-0.21)$ than the cisapride group (-0.15). Five of $17 \mathrm{pH}$ variables had significantly improved from baseline in infants who had received cisapride compared with $11 / 17$ in those receiving Gaviscon plus Carobel. However, unpaired analysis of diary and $\mathrm{pH}$ data showed no significant differences between the two groups. We conclude that first line treatment of GOR with cisapride is no more effective than conventional treatment with Gaviscon plus Carobel.
\end{abstract}

Gastro-oesophageal reflux (GOR) is a common disorder of infancy. It is frequently mild and self limiting ${ }^{12}$ but can cause serious morbidity and even mortality. ${ }^{3}$ Conventional management consists of advice on posture, the use of antacids, and thickening of feeds. ${ }^{4}$ Preliminary studies suggest that cisapride, a novel, gastrointestinal, prokinetic agent is a valuable drug in the treatment of GOR in infants and young children. ${ }^{56}$ Gaviscon, an analginate/alkaline compound (Reckitt and Colman), has been shown to diminish reflux in a double blind, placebo controlled study. ${ }^{7}$ These two forms of treatment act in very different ways. Cisapride stimulates cholinergic receptors in the enteric plexus, ${ }^{8}$ and improves both oesophageal motility ${ }^{9}$ and gastric emptying in adults, ${ }^{10}$ whereas the mode of action of Gavison is less clear cut. It is believed to form a thick, foamy raft on the surface of gastric contents, ${ }^{11}$ which coats the fundus of the stomach and protects the oesophagus from peptic ulceration. Direct buffering of gastric acid, resulting in a neutral refluxate is probably of subsidiary importance. Carobel, a thickening agent made from carob seed flour (Cow and Gate), is thought to render feeds more viscous, making regurgitation less likely. In the present study the relative effectiveness of Gaviscon plus Carobel and cisapride in infants with symptomatic GOR is assessed. We report our findings in a randomised, parallel group trial conducted over a one month period utilising both clinical criteria and lower oesophageal $\mathrm{pH}$ monitoring.

\section{Patients and methods}

PATIENTS

Fifty bottle fed infants with chronic vomiting, aged between 2 and 18 months, had GOR confirmed by 24 hour lower oesophageal pH monitoring (that is, a $\mathrm{pH}$ less than $\mathbf{4}$ for at least $5 \%$ of the recording period). None had evidence of significant neurological, respiratory, metabolic or associated gastrointestinal disease, or had received $\mathrm{H}_{2}$ antagonists, theophylline, or anticholinergic drugs. Infants were randomly allocated either oral cisapride $0.2 \mathrm{mg} / \mathrm{kg} /$ dose four times a day (group A) or infant Gaviscon half a sachet to each $90 \mathrm{ml}$ feed (group B) for four weeks. Carobel was also prescribed for those infants in group B who were not fully established on solid foods. The study was approved by the Leicester Health Authority ethics committee and informed consent was obtained from parents in all cases.

\section{CLINICAL ASSESSMENT}

Parents were provided with a diary in which a daily record of vomiting was kept. Severity was graded as follows: absent (0), $1-4$ episodes per day (1), or greater than 4 episodes per day (2). The final score was calculated by dividing the sum of the daily scores by the maximum score possible for the number of days for which records were available, range $0-1 \cdot 00$. This facilitated a comparison of scores between groups A and B, by allowing for small differences between the groups in the number of days for which diaries were kept. A subjective parental evaluation of treatment was also obtained at the end of the study.

OESOPHAGEAL $\mathrm{pH}$ MONITORING

Lower oesophagel $\mathrm{pH}$ monitoring was performed using a $2 \cdot 1 \mathrm{~mm}$ diameter flexible antimony electrode monocrysant model 91-0011 (Synectics Medical) which was passed nasally and advanced into the fasting stomach. The probe was then withdrawn to a distance equivalent to $87 \%$ of the total oesophageal length, calculated using the formula of Strobel et al. ${ }^{12}$ The semidisposable electrodes were calibrated 
before and after each test at $\mathrm{pH} 1$ and 7 at $23^{\circ} \mathrm{C}$. Electrodes were discarded if deviations of 0.2 $\mathrm{pH}$ units or more from either standard buffer occurred. A reusable silver/silver chloride reference electrode model 4011 (Synectics Medical) was secured to the chest wall and both electrodes were attached to a portable $\mathrm{pH}$ recorder and data storage system (Digitrapper Mark II, Synectics) which sampled intraoesophageal $\mathrm{pH}$ every four seconds. A reflux episode was defined as a fall in $\mathrm{pH}$ to below 4 for 15 seconds or longer. The lightweight device was easily carried by parents in a shoulder bag. No restrictions were placed on activity or diet during the 24 hour study period. On completion of each study the stored data were transferred on to an Amstrad PC 1512. Using dedicated software 'EsopHogram' (Gastrosoft Inc) the following variables were computed: (i) number of reflux episodes, (ii) number of reflux episodes $>5$ minutes, (iii) the longest reflux episode, and (iv) the percentage of the time during which reflux occurred, also known as the 'reflux index'. These were calculated for postprandial periods (within two hours of a feed), fasting periods (two hours or more after feeding), overnight ( $10 \mathrm{pm}-6 \mathrm{am})$, and the total recording time. The total number of episodes and the number of episodes $>5$ minutes were expressed as an average rate per hour to allow for individual variations in the number and duration of feeds. Acid clearance values for postprandial and fasting periods were also calculated and expressed as minutes per reflux episode.
Table 1 Patient details at recruitment. ${ }^{*}$ Results are median (range)

\begin{tabular}{lll}
\hline & $\begin{array}{l}\text { Group A: } \\
\text { cisapride } \\
(n=26)\end{array}$ & $\begin{array}{l}\text { Group B: } \\
\text { Gaviscon } \\
(n=24)\end{array}$ \\
\hline Age (months) & $4 \cdot 0(2-18)$ & $4 \cdot 5(2-17)$ \\
Weight (kg) & $6 \cdot 5(3 \cdot 0-15 \cdot 0)$ & $6 \cdot 3(3 \cdot 9-8 \cdot 9)$ \\
Total reflux index (\%) & $15 \cdot 3(5 \cdot 3-71 \cdot 0)$ & $15 \cdot 0(5 \cdot 1-36 \cdot 5)$ \\
Vomiting score $(0-1 \cdot 00)$ & $0 \cdot 73(0 \cdot 29-1)$ & $0 \cdot 69(0 \cdot 23-1)$ \\
Male:female ratio & $15: 11$ & $15: 9$ \\
\hline
\end{tabular}

There was no significant difference between groups A and B for any variable by Mann-Whitney U test.

Table 2 Oesophageal $p H$ results in group $A$ (cisapride, $n=26$ ). Results are median (range)

\begin{tabular}{|c|c|c|c|}
\hline & Before treatment & After treatment & $\begin{array}{l}\text { Wilcoxon } \\
\text { signed } \\
\text { rank test }\end{array}$ \\
\hline \multicolumn{4}{|l|}{ Postprandial: } \\
\hline No of episodes/hour & $2 \cdot 4(0 \cdot 6-15 \cdot 0)$ & $1 \cdot 8(0 \cdot 1-10 \cdot 1)$ & NS \\
\hline No of episodes $>5 \mathrm{~min} /$ hour & $0.5(0.0-10 \cdot 0)$ & $0 \cdot 3(0 \cdot 0-1 \cdot 3)$ & NS \\
\hline $\begin{array}{l}\text { LRE (min) } \\
\text { Reflux index }(\%)\end{array}$ & $\begin{array}{l}26 \cdot 0(4 \cdot 0-120 \cdot 0) \\
20 \cdot 1(4 \cdot 9-62 \cdot 0)\end{array}$ & $\begin{array}{l}1.3(1 \cdot 0-120 \cdot 0) \\
10.9(1 \cdot 8-60 \cdot 0)\end{array}$ & NS \\
\hline Clearance $(\mathrm{min} / \mathrm{reflux})$ & $3 \cdot 1(0 \cdot 5-20 \cdot 0)$ & $2 \cdot 6(0 \cdot 1-14 \cdot 0)$ & $\mathrm{p}<0.01$ \\
\hline \multicolumn{4}{|l|}{ Fasting: } \\
\hline No of episodes/hour & $1 \cdot 6(0 \cdot 5-3 \cdot 2)$ & $1 \cdot 4(0 \cdot 4-6 \cdot 5)$ & NS \\
\hline $\begin{array}{l}\text { No of episodes }>5 \mathrm{~min} / \text { hour } \\
\text { LRE (min) }\end{array}$ & $\begin{array}{c}0 \cdot 5(0 \cdot 0-1 \cdot 2) \\
31 \cdot 0(2 \cdot 0-301 \cdot 0)\end{array}$ & $\begin{array}{c}0 \cdot 2(0 \cdot 0-1 \cdot 2) \\
22 \cdot 0(1 \cdot 0-244 \cdot 0)\end{array}$ & $\begin{array}{l}\text { p }<0.05 \\
\text { NS }\end{array}$ \\
\hline Reflux index $(\%)$ & $13.6(0 \cdot 7-92 \cdot 0)$ & $8 \cdot 7(0 \cdot 3-90 \cdot 0)$ & $\mathrm{p}<0.05$ \\
\hline \multirow{2}{*}{\multicolumn{4}{|c|}{ Overnight: . }} \\
\hline & & & \\
\hline No of episodes/hour & $1 \cdot 1(0 \cdot 0-3 \cdot 6)$ & $0 \cdot 6(0 \cdot 0-7 \cdot 1)$ & NS \\
\hline No of episodes $>5 \mathrm{~min} /$ hour & $0.4(0.0-1 \cdot 0)$ & $0.1(0.0-1.5)$ & NS \\
\hline LRE (min) & $28 \cdot 0(0 \cdot 0-172 \cdot 0)$ & $6 \cdot 5(0 \cdot 0-102$ & NS \\
\hline Reflux index (\%) & $10 \cdot 4(0.0-60 \cdot 7)$ & $5.8(0.0-85.4)$ & NS \\
\hline \multicolumn{4}{|l|}{ Total: } \\
\hline No of episodes/hour & $2 \cdot 0(0 \cdot 9-10 \cdot 8)$ & $1 \cdot 7(0 \cdot 1-7 \cdot 9)$ & NS \\
\hline No of episodes $>5 \mathrm{~min} / \mathrm{hour}$ & $0.5(0 \cdot 0-1 \cdot 0)$ & $0 \cdot 2(0 \cdot 0-1 \cdot 2)$ & $\mathrm{p}<0.05$ \\
\hline Reflux index (\%) & $15 \cdot 3(5 \cdot 3-57 \cdot 5)$ & $9 \cdot 5(0 \cdot 3-82 \cdot 8)$ & $\mathrm{p}<0.05$ \\
\hline
\end{tabular}

LRE = longest reflux episode.

\section{STATISTICAL METHODS}

Contingency tables were constructed and $\chi^{2}$ tests with Yates's correction factor were employed to determine the significance of differences in parental assessment between the two treatments. As the ages of infants, diary scores, and $\mathrm{pH}$ variables were not normally distributed non-parametric tests were employed. Changes in $\mathrm{pH}$ variables after treatment were analysed using Wilcoxon signed rank tests and significance was defined as $\mathrm{p}<0.05$. Median values were calculated for $\mathrm{pH}$ variables. Differences between the two groups were assessed using the Mann-Whitney U test.

\section{Results}

All 50 infants completed the study. Twenty six had received cisapride (group A) and 24 Gaviscon (group B). Twenty one of the latter group were also given Carobel (1-2 scoops to each $90 \mathrm{ml}$ feed). Table 1 gives clinical details of the two groups which were comparable in age, weight, reflux indices, and symptom scores during the pretreatment phase. Both medications were well tolerated; in group A two infants developed mild diarrhoea which did not interfere with the study, and another, after completion of the trial, had oesophagitis diagnosed at endoscopy while receiving cisapride.

\section{SUBJECTIVE PARENTAL EVALUATION}

Fourteen of 26 infants (53\%) on cisapride were considered to have improved compared with 19/24 (79\%) of those on Gaviscon plus Carobel, $\mathrm{p}=0.055\left(\chi^{2}\right.$ test $)$.

DIARY SCORES

Scores for the 'run in' period and only the last two weeks of treatment were analysed. In group A 22/26 diaries were sufficiently complete for analysis, 16/22 (72.7\%) had improved scores, median change -0.15 with $95 \%$ confidence intervals -0.26 to $-0.01, p<0.05$. In group $B$ $18 / 24$ diaries were suitable for analysis. Fifteen out of $18(83.8 \%)$ had improved, median change -0.21 with $95 \%$ confidence intervals -0.39 to $-0.11, p<0.01$. The difference between the changes that occurred on treatment in the groups was not statistically significant (MannWhitney U test).

\section{OESOPHAGEAL $\mathrm{pH}$ MEASUREMENTS}

Seventeen variables were analysed in each group (tables 2 and 3). In group A 5/17 showed significant improvement compared with 11/17 in group B. The reflux index and the number of episodes exceeding five minutes improved on both treatments. Direct comparison between the two groups of changes in each $\mathrm{pH}$ variable revealed no significant differences.

\section{Discussion}

The clinical importance of uncomplicated GOR is a matter for debate. In the absence of overt oesophagitis, failure to thrive, apnoeic spells, or 
Table 3 Oesophageal $p H$ results in group $B($ Gaviscon plus Carobel, $n=24)$. Results are median (range)

\begin{tabular}{|c|c|c|c|}
\hline & Before treatment & After treatment & $\begin{array}{l}\text { Wilcoxon } \\
\text { signed } \\
\text { rank test }\end{array}$ \\
\hline \multicolumn{4}{|l|}{ Postprandial: } \\
\hline No of episodes/hour & $2 \cdot 1(0 \cdot 0-5 \cdot 9)$ & $1 \cdot 3(0 \cdot 0-4 \cdot 2)$ & \\
\hline No of episodes $>5 \mathrm{~min} /$ hour & $0 \cdot 3(0 \cdot 0-1 \cdot 2)$ & $0.1(0.0-0.8)$ & $p<0.01$ \\
\hline $\operatorname{LRE}(\min )$ & $25 \cdot 0(0 \cdot 0-99 \cdot 0)$ & $8 \cdot 0(1 \cdot 0-120 \cdot 0)$ & NS \\
\hline Reflux index $(\%)$ & $12 \cdot 0(5 \cdot 0-48 \cdot 8)$ & $5.8(0.0-33 \cdot 3)$ & $\mathrm{p}<0.05$ \\
\hline Clearance ( $\mathrm{min} /$ reflux $)$ & $4 \cdot 2(0 \cdot 0-17 \cdot 2)$ & $4 \cdot 0(0 \cdot 0-31 \cdot 0)$ & NS \\
\hline \multicolumn{4}{|l|}{ Fasting: } \\
\hline No of episodes/hour & $1.5(0.3-3 \cdot 0)$ & $1 \cdot 2(0 \cdot 6-3 \cdot 5)$ & NS \\
\hline No of episodes $>5 \mathrm{~min} / \mathrm{hour}$ & $0.4(0.0-0.8)$ & $0.2(0 \cdot 0-0.9)$ & $\mathrm{p}<0 \cdot 01$ \\
\hline LRE (min) & $37 \cdot 5(4 \cdot 0-140 \cdot 0)$ & $12 \cdot 0(0 \cdot 0-300 \cdot 0)$ & $\mathrm{p}<0.01$ \\
\hline Reflux index $(\%)$ & $16.5(4 \cdot 9-61 \cdot 0)$ & $7 \cdot 1(0 \cdot 6-52 \cdot 7)$ & $\mathrm{p}<0.01$ \\
\hline Clearance (min/reflux) & $6.9(1 \cdot 2-34 \cdot 9)$ & $3.5(0.6-13.8)$ & $\mathrm{p}<0.05$ \\
\hline \multicolumn{4}{|l|}{ Overnight: } \\
\hline No of episodes/hour & $0.9(0.0-3.6)$ & $0.4(0.0-1.9)$ & NS \\
\hline No of episodes $>5 \mathrm{~min} / \mathrm{hour}$ & $0 \cdot 3(0 \cdot 0-0 \cdot 7)$ & $0.1(0.0-0.6)$ & $\mathrm{p}<0.05$ \\
\hline LRE $(\min )$ & $33 \cdot 9(0 \cdot 0-128 \cdot 0)$ & $7 \cdot 0(0 \cdot 0-252 \cdot 0)$ & $\mathrm{p}<0.05$ \\
\hline Reflux index (\%) & $10 \cdot 1(0 \cdot 6-60 \cdot 7)$ & $4 \cdot 0(0 \cdot 0-80 \cdot 4)$ & $p<0.05$ \\
\hline \multicolumn{4}{|l|}{ Total: } \\
\hline No of episodes/hour & $1.8(0.4-6.9)$ & $1.4(0.4-3.4)$ & NS \\
\hline No of episodes $>5 \mathrm{~min} / \mathrm{hour}$ & $0.4(0 \cdot 1-0 \cdot 7)$ & $0 \cdot 1(0 \cdot 0-0.6)$ & $\mathrm{p}<0.01$ \\
\hline Reflux index $(\%)$ & $15 \cdot 0(5 \cdot 1-36 \cdot 5)$ & $5 \cdot 4(1 \cdot 9-42 \cdot 3)$ & $\mathrm{p}<0.01$ \\
\hline
\end{tabular}

$\mathrm{LRE}=$ longest reflux episode. sphincter (LOS) relaxations that result in more frequent reflux episodes. ${ }^{13}$ The more rapid acid clearance values seen in the postprandial period of patients receiving cisapride suggest an early improvement in oesophageal motility. Phasic LOS relaxations are putatively responsible for the majority of reflux episodes, but low basal tone accounts for $20 \%$ of episodes ${ }^{14}$ and becomes more important as oesophagitis progresses. ${ }^{15}$ Motility studies in vomiting infants have shown that cisapride improves LOS tone ${ }^{6}$ but concurrent $\mathrm{pH}$ studies in such infants failed to show a reduction in the number of reflux episodes, which reflects the degree of competence of the LOS. In the present study, no significant effect on the number of reflux episodes was observed in patients who received either treatment.

GOR occurs less frequently in the sleeping state than in wakefulness, ${ }^{16}$ but the degree of overnight reflux may be predictive for the development of stricture and the need for antireflux surgery. ${ }^{17}$ Gaviscon plus Carobel reduced these overnight measures of GOR severity considerably (table 3 ) whereas the changes achieved by cisapride were not significant.

One difficulty in interpreting the results of $\mathrm{pH}$ studies in infants with GOR is the buffering effect of milk on acid resulting in neutral reflux. Some investigators have overcome this problem by acidifying feeds during the test period. This is not feasible in any study with Gaviscon because acid added to feeds would have been neutralised by the alginate/alkali compound. The mechanism(s) whereby Gaviscon exerts a therapeutic effect is not fully known. It produces a viscous raft on the surface of gastric contents protecting the oesophagus from acid reflux. However, a recent study has shown that Gaviscon must be taken 30 minutes after food for raft formation to occur. ${ }^{18}$ It did not occur when the drug was taken before or with a meal. Moreover, Laitinen et al have shown that sucralfate and Gaviscon taken 30 minutes before meals (when raft formation is unlikely) relieved symptoms and healed oesophagitis. ${ }^{19}$ It is unlikely that the effects of Gaviscon are due to its buffering properties as Gaviscon is not primarily an anticid. Any such effect would have been least during fasting and overnight when feeding is infrequent. However, significant improvement was observed at these times after treatment; acid clearance times were also more rapid and in keeping with the improvements seen in vomiting scores. These findings suggest that Gaviscon improves motility indirectly, perhaps by alleviating oseophagitis, which is a recognised cause of impaired oeosphageal motor function. ${ }^{15}{ }^{20}$ Alternatively, Gaviscon in the lower oesophagus may have coated the $\mathrm{pH}$ electrode rendering the $\mathrm{pH}$ data uninterpretable. This is unlikely as electrode coating was not observed in an in vitro study of Gaviscon. ${ }^{21}$

As judged from pretreatment $\mathrm{pH}$ data, many infants had severe GOR and perhaps oesophagitis. ${ }^{22}$ Routine endoscopy in infants presenting de novo with symptoms of GOR was not undertaken. None had received Gaviscon or cisapride before inclusion in the study and it seemed 
reasonable to proceed conservatively and treat with one or other regimen in the first instance. A poor response would have prompted investigation, and by this criterion only one infant was assessed endoscopically.

No attempt was made to assess the individual contribution of Carobel as our aim was to compare the new medication, cisapride, with conventional treatment, including Carobel. ${ }^{4} \mathrm{~A}$ previous study has shown that Carobel alone improves reflux severity but that it is not as effective as cisapride in reducing vomiting due to GOR. ${ }^{8}$ There were too few patients to allow comparison between the infants treated with Gaviscon plus Carobel and those with Gaviscon alone. Two previous studies, however, have shown that feed thickening may increase rather than decrease acid exposure in the lower oesophagus. ${ }^{23-24}$

Another potential difficulty relates to the degree of reproducibility of $\mathrm{pH}$ studies. Vandenplas $e t$ al found good correlation between results performed on consecutive days in the same group of patients, ${ }^{25}$ whereas Hampton $e t$ al found a fourfold variation in results from tests done on consecutive days. ${ }^{26}$ Simultaneous lower oesophageal $\mathrm{pH}$ monitoring with two probes shows good agreement, ${ }^{27}$ which suggests that this variability is related more to biological than to technical factors. There is little doubt that lower oesophageal $\mathrm{pH}$ measurement is very useful diagnostically, but because of variations in the severity of GOR over relatively short periods of time, its value in following the progress of patients on medication may be more limited.

Significant reflux can sometimes occur in the absence of vomiting. ${ }^{28}$ However, we chose to regard vomiting as one indicator of reflux severity because it was easy to observe and objective. Features such as irritability, 'chestiness', and poor feeding were rejected as too subjective and not specific for GOR. In the absence of a 'gold standard' method for monitoring the progress of GOR, it seemed reasonable to combine parental impressions, diary score assessments, and the findings from lower oesophageal $\mathrm{pH}$ studies to determine the response to treatment of the infants studied despite the recognised limitations of each assessment method.

In conclusion, cisapride is no more, and perhaps less effective than conventional treatment with Gaviscon plus Carobel. Thus, in GOR in infancy, the current practice of prescribing Gaviscon plus Carobel as first line treatment appears justified. However, our findings raise further questions. Should endoscopic assessment be a primary investigation in infants presenting with severe GOR as the presence of oesophagitis might indicate the need for an $\mathrm{H}_{2}$ antagonist in addition to standard treatments. Further studies are also needed to clarify the relative efficacy of Gaviscon and Carobel.
We wish to thank Janssen Pharmaceuticals for providing generous financial support, the paediatricians at Leicester Royal Infirmary for referring patients and, not least, the parents who volunteered their children for this study.

1 Carré IJ. The natural history of partial thoracic stomach "hiatal hernia' in children. Arch Dis Child 1959;34:344-7.

2 Darling DB, Fisher JH, Gellis SS. Hiatal hernia and gastroesophageal reflux in infants and children: analysis of incidence of North American children. Pediatrics 1974;54:450-5.

3 Herbst JJ. Gastro-esophageal reflux. F Pediatr 1981;98:860-70.

4 Carré IJ. Management of gastro-oesophageal reflux. Arch Dis Child 1985;60:70-5.

5 Cucchiara S, Staiano A, Capozzi C, Lorenzo C, Boccieri A, Auricchio S. Cisapride for gastro-oesophageal reflux and peptic oesophagitis. Arch Dis Child 1987;62:454-7.

6 Cucchiara S, Staiano A, Boccieri A, et al. Effects of cisapride on parameters of oesophageal motility and on the intraoesophageal $\mathrm{pH}$ test in infants with gastro-oesophageal reflux disease. Gut 1990;31:21-5.

7 Buts JP, Barudi C, Otte JB. Double-blind controlled study on the efficacy of sodium alginate (Gaviscon) in reducing gastrooesophageal reflux assessed by 24 hour continuous pH monitoring in infants and children. Eur $\mathcal{f}$ Pediatr 1987;146: monitoring 8 .

8 Schuurkes JAJ, Van Nueten JM, Van Daele PGH, Reyntjens AJ, Janssen PAJ. Motor stimulating properties of cisapride on isolated gastrointestinal preparations of the guinea pig. f Pharmacol Exp Ther 1985;234:775-83.

9 Gilbert RJ, Dodds WJ, Kahrilas PJ, Hogan WJ, Lipman S. Double blind assessment of intravenous and oral cisapride on oesophageal motor function. Digestion 1986;34:139-43.

10 Jian R, Ducrot F, Piedeloup C, Mary JY, Najean Y, Bernier JJ. Measurement of gastric emptying in dyspeptic patients:
effect of a new gastrokinetic agent (cisapride). Gut 1985;26: 352-8.

11 Stanciu C, Bennett JR. Alginate/antacid in the reduction of gastro-oesophageal reflux. Lancet 1974;i:109-11.

12 Strobel CT, Byrne WJ, Ament ME, Euler AR. Correlation of oesophageal lengths in children with height: application to the Tuttle test without prior esophageal manometry. the Tuttle test without

13 Holloway RH, Hongo M, Berger K, McCallum RW. Gastric distension: a mechanism for post prandial reflux. Gastrodistension: a mechanism

14 Dent J, Holloway RH, Touli J, Dodds WJ. Mechanisms of sphincter incompetence in patients with symptomatic gastrooesophageal reflux. Gastroenterology 1988;29:1020-8.

15 Cucchiara S, Staiano A, Dilcrezzo C. Esophageal motor abnormalities in children with gastro-esophageal reflux and peptic ulceration. F Pediatr 1986;108:907-10.

16 Berquist WE, Ament ME. Upper GI function in sleeping infants. Am Rev Respir Dis 1985;131(suppl):S26-9.

17 Colson DJ, Campbell CA, Wright VA, Watson BW. Predictive value of oesophageal $\mathrm{pH}$ variables in children with gastrooesophageal reflux. Gut 1990;31:370-3.

18 Washington N, Greaves JL, Wilson CG. Effect of time dosing relative to a meal on the raft formation of anti-reflux agent. f Pharm Pharmacol 1990;42:50-3.

19 Laitinen S, Stahlberg M, Kairaluamo MI, et al. Sucralfate and alginate/antacid in reflux oesophagitis. Scand $\mathcal{f}$ Gastroenterol 1985;20:229-32.

20 Sondheimer JM. Gastroesophageal reflux: update on pathogenesis and diagnosis. Pediatr Clin North Am 1988;35: genesis

21 Vatier J, Vitre MI, Vallot I, Mignon M. pH gradient support and antacid action of gastro-oesophageal coating agents. 'In vitro' pharmacologic study using a model of the artificial 'stomach'. Gastroenterol Clin Biol 1990;14:414-22.

22 Baer M, Maki M, Nurminen J, Turjanma V, Pukander J, Vesikara T. Esophagitis and findings of long term esophageal pH recording in children with repeated lower respiratory tract symptoms. F Pediatr Gastroenterol Nutr 1986;5:187-90.

23 Vandenplas Y, Sacre Smits L. Gastro-oesophageal reflux in infants by pH monitoring. Eur 7 Pediatr 1987;146:504-7.

24 Bailey DJ, Andres JM, Danek GD, Pineiro-Carrero VM. Lack of efficacy of thickening feeding as treatment for gastrooesophageal reflux. $\mathcal{F}$ Pediatr 1987;110:187-9.

25 Vandenplas Y, Helven R, Goyvaerts L, Sacré L. Reproducibility of continuous 24-hour $\mathrm{pH}$ studies in infants. Gut 1990;31:374-7.

26 Hampton FJ, MacFadyen UM, Simpson H. Reproducibility of 24-hour oesophageal pH studies in infants. Arch Dis Child 1990;65:1249-54.

27 Hampton FJ, MacFayden UM, Mayberry JF. Variability in results of simultaneous ambulatory oesophageal $\mathrm{pH}$ monitoring. Dig Dis Sci 1992(in press).

28 Paton JY, Nanayakkhara CS, Simpson H. Vomiting and gastrooesophageal reflux. Arch Dis Child 1988;63:837-8. 